\title{
Redes animadas: a coprodução nas séries de animação brasileiras
}

\author{
Animated networks: co-production in Brazilian animation series
}

\author{
Natacha Stefanini Canesso' (1)
}

\section{RESUMO}

O objetivo deste artigo foi apresentar o cenário da coprodução nas obras de animação seriada das produtoras independentes brasileiras que aprovaram projetos na Chamada Pública 2012 para produção de série de animação no Programa de Apoio ao Desenvolvimento do Audiovisual Brasileiro (Prodav 01/2012). A coprodução foi analisada como um condicionante do mercado que dialoga com outros condicionantes presentes nos ambientes externo e interno das produtoras independentes brasileiras e que impacta nos processos criativos e decisórios dos profissionais envolvidos nos projetos e nos resultados obtidos com a obra. Kotler e Armstrong (2015) e Kotler e Keller (2016) pautam o referencial teórico-metodológico da pesquisa qualitativa baseada em análise de matérias, reportagens e entrevistas, em observação participativa do mercado de animação e entrevistas com gestores das produtoras. As coproduções de obras de animação seriada que se tornaram referências no mercado brasileiro são resgatadas por Gatti Junior, Gonçalves e Barbosa (2014) e complementadas com as experiências de outras nove produtoras investigadas. São apontados os objetivos, as características das coproduções e os diálogos estabelecidos com os canais fechados. Conclui-se que foram alcançados bons resultados em coprodução com as obras selecionadas na Chamada Pública Prodav 01/2012: os profissionais envolvidos se especializaram a partir dos diálogos com seus parceiros, e as produtoras consolidaram seus negócios. Mas o atual contexto nacional de produção de animação seriada apresenta fragilidades para a manutenção de fluxo contínuo de produção, para o diálogo intermitente com canais e demais parceiros nacionais e internacionais e para a consolidação das redes de negócios.

Palavras-chave: animação seriada; coprodução de obra de animação seriada; Prodav 01/2012.

\begin{abstract}
The purpose of this article was to present the scenario of co-production in animation series by Brazilian independent producers that were approved for production in the 2012 Public Call Brazilian Audiovisual Development Support Program (Prodav 01/2012). Co-production was analyzed as a condition of the market that dialogues with other conditions present in the external and internal environments of Brazilian independent producers and that impacts the creative and decision-making processes of the professionals involved in the projects and on the results obtained with the animation series. Kotler, Armstrong (2015); Kotler, Keller (2016) guide the theoretical-methodological framework of qualitative research based on the analysis of articles, reports and interviews, on participatory observation of the animation market and interviews with managers of producers. The co-productions of serial animation works that have become references in the Brazilian market are rescued through Gatti Junior, Gonçalves and Barbosa (2014) and complemented with the experiences of nine other investigated producers. The objectives, characteristics of the co-productions and the dialogues established with closed channels are pointed out. It is concluded that good results were achieved with the co-productions in animation series selected in the Public Call Prodav 01/2012: the professionals involved became specialized through dialogues with their partners and the producers consolidated their businesses. But the current national context of serial animation production presents weaknesses for the maintenance of a continuous production flow, for the intermittent dialogue with channels and other national and international partners and for the consolidation of business networks.
\end{abstract}

Keywords: animation series; co-production of serial animation; Prodav 01/2012.

'Universidade Federal do Oeste da Bahia - Santa Maria de Vitória (BA), Brasil. E-mail: nscanesso5@gmail.com Recebido em: 18/06/2021 - Aceito em: 14/10/2021 


\section{INTRODUÇÃO}

As séries brasileiras de animação produzidas para televisão ganharam destaque na audiência dos canais fechados a partir de 2009. Peixonauta, a primeira coprodução de animação nacional, foi líder de audiência entre crianças de quatro a 11 anos em seus horários de exibição (IBOPE, 2009). A parceria foi firmada entre a produtora brasileira TV Pinguim e o canal internacional Discovery Kids para produção de 52 episódios distribuídos em mais de 70 países e também exibidos em canais abertos, a exemplo do SBT e da TV Cultura.

Cinco anos depois, a produtora repetiu o sucesso com O Show da Luna em um mercado considerado promissor pelos seus agentes, já que incluía a veiculação de outras dez obras brasileiras de animação seriada, cerca de outros 30 projetos em desenvolvimento a partir de fomento público, investimentos de mais dois canais internacionais em programação infantil - Cartoon Network e Nickelodeon - e a aprovação da Lei $n^{\circ}$ 12.485/2011 (BRASIL, 2011), também conhecida como Lei da TV paga (FONSECA, 2012). As produtoras independentes brasileiras que participavam desse contexto e investiam em animação exploravam as possibilidades de coprodução de séries.

O objetivo deste artigo é apresentar o cenário da coprodução nas obras de animação seriada das produtoras independentes brasileiras que aprovaram projetos na Chamada Pública Programa de Apoio ao Desenvolvimento do Audiovisual Brasileiro (Prodav) 01/2012. O Prodav integrou a política pública de incentivo ao audiovisual nacional para a exploração comercial inicial nas janelas de radiodifusão de sons e imagens. A Chamada Pública Prodav 01/2012 foi dedicada ao fomento de produção de obra audiovisual em formato de série de ficção e animação e documentário.

Neste trabalho estão destacadas as experiências de coprodução das seguintes empresas: Birdo Filmes de Animação, Boutique Filmes e Produções, Cabong Studios, Copa Studio, Origem Comunicação, Otto Desenhos Animados, Tortuga Studios, Zoom Elefante, 44 Toons. A coprodução é compreendida como um condicionante do mercado da animação seriada e, como tal, configura-se como uma variável em constante diálogo com os processos criativos dos profissionais envolvidos nos processos criativos e decisórios da obra. Trata-se de um recorte da pesquisa de doutorado que investigou os processos criativos na gestão da animação seriada infantil brasileira, realizada no Programa de Pós-Graduação em Comunicação e Cultura Contemporâneas da Universidade Federal da Bahia, com apoio da Fundação de Amparo à Pesquisa do Estado da Bahia, finalizada em 2020.

Como procedimento metodológico, foi realizada a análise de matérias, reportagens e entrevistas disponíveis na internet, nos sites e nas redes sociais das produtoras selecionadas, de 2012 a 2019, e dos relatórios do Fórum Anima Mundi, de 2012 a 2019. O levantamento de dados primários foi realizado pela observação do mercado, com a participação em eventos com profissionais do audiovisual, e a animação e realização de entrevistas com gestores das produtoras. O artigo está dividido em quatro partes, além desta introdução e da conclusão: 
1. condicionantes do mercado de animação seriada;

2. referências brasileiras de coprodução;

3. objetivos e características da coprodução;

4. o diálogo com os canais.

\section{CONDICIONANTES DO MERCADO DE ANIMAÇÃO SERIADA}

Os condicionantes tratados neste trabalho foram obtidos com a análise do mercado de animação e aprimorados a partir dos princípios de marketing, que atendem à análise de ambientes organizacionais e elaboração de planos estratégicos de marketing e comunicação. A orientação dos autores da área para tal elaboração é inicialmente levantar informações sobre a organização (empresa) e sobre os atores sociais próximos a ela, os que afetam sua capacidade de atender aos seus clientes, e sobre as forças sociais que afetam esses atores sociais. O conjunto de atores sociais é denominado microambiente e o conjunto de forças sociais, macroambiente. Juntos, microambiente e macroambiente compõem o ambiente de marketing (KOTLER; KELLER, 2016; KOTLER; ARMSTRONG, 2015).

No macroambiente estão as condições comuns a todas as organizações que atuam em determinado mercado. São fatores econômicos, socioculturais, político-legais, tecnológicos e ambientais. As variáveis desse ambiente são classificadas pelos autores da área de marketing como incontroláveis pelas organizações, ou seja, estas não podem interferir individualmente e diretamente nas forças sociais para gerar alterações de mercado. A depender da condição objetiva de uma empresa, dos seus recursos materiais e humanos, das suas práticas diárias e das relações que estabelece no seu microambiente, as variáveis do macroambiente podem se tornar oportunidades ou ameaças no planejamento e condução dos negócios (KOTLER; KELLER, 2016, p. 97-99).

Assim, essas forças sociais podem compor um contexto amplo e comum de condicionantes externos aos processos criativos da produtora e atuarem no microambiente, ou seja, no conjunto de atores sociais com os quais a produtora se relaciona. O microambiente é composto da própria empresa, de seus fornecedores, empresas intermediárias de mercado, concorrentes, públicos em geral e clientes.

No contexto específico de cada produtora, foi analisada a relação da produtora independente com os atores sociais do microambiente no processo de entrega de uma série de animação com potencial de engajamento do público infantil. Kotler e Armstrong (2015, p. 201) explicam que a criação de valor e consequente engajamento do público é resultado das seguintes estratégias: segmentação, diferenciação e posicionamento. No caso do mercado de produção independente de animação, a segmentação é a escolha que a produtora faz acerca de para qual público produzir; a diferenciação é a relação que a obra produzida estabelece com outras obras direcionadas ao mesmo público, comparando formato, linguagem, conteúdo e qualidade técnica; o posicionamento é como essa diferenciação é interpretada e lembrada pela audiência. 
Portanto, os condicionantes externos dos processos criativos nas produtoras independentes brasileiras foram definidos a partir de forças sociais (macroambiente) e atores sociais (microambiente). O ponto de partida da investigação foi uma chamada pública para produção de uma obra para televisão (que incluía a possibilidade de produção de série de animação), o Prodav 01/2012. Como forças sociais, no cenário havia a política pública para o audiovisual, programas específicos para desenvolvimento do mercado nacional de animação e a tramitação da Lei da TV paga, que incentivou a produção e circulação de conteúdo nacional independente nos canais de televisão fechada. À época, o destaque estava nos fatores políticos-legais do macroambiente e nos atores sociais do microambiente envolvidos no fomento e financiamento das obras, incluindo os canais, que ditaram as regras para segmentação, diferenciação e posicionamento. O Quadro 1 resume os condicionantes externos: leis, programas de fomento e eventos (feiras e festivais) do macroambiente; coprodução, comercialização/distribuição e comunicação /divulgação do microambiente.

Quadro 1. Quadro-resumo dos condicionantes externos da produção independente da animação seriada infantil no Brasil.

\begin{tabular}{|l|l|c|c|}
\hline Ambiente externo & Contextualização & Condicionantes externos \\
\hline Macroambiente & Forças sociais & $\begin{array}{c}\text { Leis } \\
\text { Cenário sociocultural, eco- } \\
\text { nômico, político e legal }\end{array}$ & $\begin{array}{c}\text { Programas de fomento } \\
\text { Eventos internacionais e } \\
\text { nacionais (feiras e festivais) }\end{array}$ \\
\hline Microambiente & Atores sociais & Empresas/instituiçães & $\begin{array}{c}\text { Coprodução } \\
\text { Comercialização/distribuição } \\
\text { Comunicação/divulgação }\end{array}$ \\
\hline
\end{tabular}

Fonte: elaborado pela autora.

Para a análise dos condicionantes externos, o levantamento de informações socioculturais, econômicas, políticas e legais oferece condições de estabelecer o cenário no qual as produtoras atuam, ou seja, o macroambiente. Mas a proposta teórica de marketing também invoca os atores sociais, sendo indispensável pensar em quem compõe esse ambiente. São estes que permitem compreender a relação indivíduo/ambiente, a atuação e importância das empresas/instituições e, portanto, os condicionantes do ambiente externo referentes ao microambiente.

Já os condicionantes internos são inerentes à produtora e incluem: seu perfil, aqui definido como produtora de conteúdo, estúdio de animação ou produtora de audiovisual; sua localização geográfica; seus conhecimentos e a experiência da equipe. Apesar de estarem aqui sistematizados e separados, é importante destacar que os condicionantes externos e internos são, na prática profissional, intrincados. Sob a ótica dos gestores dos projetos, os condicionantes externos e internos compõem um sistema sem limites específicos no qual outras variáveis estão presentes e, portanto, outros condicionantes podem ser definidos, sem necessariamente a reflexão como variáveis isoladas. Pesquisas futuras podem, por exemplo, refletir sobre tecnologia desenvolvida/adotada, enquanto condicionante externo, e porte e faturamento, enquanto condicionante interno. 
A seguir, o Quadro 2 contém a síntese dos condicionantes externos e internos propostos nesta investigação.

Desses condicionantes, a coprodução foi identificada como central nos processos de gestão das obras e pautou o diálogo com os demais condicionantes na análise apresentada a seguir.

Quadro 2. Condicionantes da produção independente da animação seriada infantil no Brasil.

\begin{tabular}{|l|c|}
\hline \multicolumn{2}{|c|}{ Condicionantes } \\
\hline Externos & Leis \\
Forças sociais & $\begin{array}{c}\text { Programas de fomento } \\
\text { Eventos nacionais e internacionais }\end{array}$ \\
\hline Externos & Coprodução \\
Atores sociais & Comercialização/distribuição \\
Comunicação/divulgação
\end{tabular}

Fonte: elaborado pela autora com base em Kotler e Keller, 2016 e Kotler e Armstrong, 2015.

\section{REFERÊNCIAS BRASILEIRAS DE COPRODUÇÃO}

$O$ projeto realizado em associação com empresas do mercado audiovisual nacional e/ou internacional é definido como coprodução (BRASIL; ANCINE 2001). $O$ acordo pode ser firmado a partir de um conceito, nas fases de desenvolvimento, pré-produção ou produção da obra, e, no caso da animação seriada infantil no Brasil, acontece entre produtoras nacionais, entre produtoras e canais/streaming e/ ou entre produtoras nacionais e internacionais.

O contrato assinado pelas produtoras implica em porcentagem de detenção dos direitos patrimoniais sobre a obra. Direitos patrimoniais são uma "categoria de direitos de autor com repercussão econômica, suscetíveis de exploração, nos termos, limites e exceções previstos na legislação" (BRASIL, 2012). Se o percentual de direitos patrimoniais concedido às empresas internacionais for superior ao da produtora brasileira, a obra não é considerada nacional. No caso de obras submetidas às chamadas públicas do Prodav, seu regimento geral rege as regras sobre distribuição de direitos patrimoniais e as obras são necessariamente brasileiras.

Um estudo de caso realizado por Gatti Junior, Gonçalves e Barbosa (2014) destaca duas coproduções internacionais que se tornaram referências para as negociações das produtoras independentes nacionais - Princesas do Mar, da Flamma, e Meu Amigãozão, da 2DLab - e uma coprodução com canal de TV no Brasil: Peixonauta, da TV Pinguim.

A Flamma enveredou na coprodução internacional porque a produtora, fundada em 2004, não atendia aos requisitos de experiência e ao histórico de produções exigidos pelos mecanismos públicos de fomento no país. A trajetória de um dos sócios como executivo de vendas de uma empresa internacional de distribuiç̧ão de conteúdo, a Mega Distribuidora, responsável pelas marcas Nelvana, Southern Star, Disney, $B B C$ e Nintendo, conduziu o projeto às possibilidades de coprodução internacional. 
Foram 25 pitchings realizados na Marché International des Programmes de Communication, em 2004, com o objetivo de fechar contrato de coprodução e realizar a animação no Brasil. A animação da série seria feita por estúdios brasileiros contatados pela Flamma, porque como produtora de conteúdo não teria equipe para produzir animação. Entretanto a ausência de projetos brasileiros de séries de animação no mercado internacional na época resultou em resistência por parte dos parceiros com relação à animação a ser produzida no Brasil.

A negociação implicou em grandes concessões, mas segundo Gatti Junior, Gonçalves e Barbosa (2014), "o objetivo foi concretizado. A estratégia era viabilizar um primeiro projeto para dar visibilidade à empresa e com isso avançar em novos trabalhos". Princesas do Mar foi coproduzida com a Southern Star, a maior produtora independente australiana, e o estúdio espanhol Neptuno Films produziu as animações.

No caso de Princesas do Mar, os australianos foram os responsáveis pela captação de recursos para a viabilização do projeto e os detentores dos direitos de propriedade. A Flamma negociou o direito de distribuição e exploração de licenciamento da série na América Latina. A experiência da Flamma difere da coprodução realizada pela $2 \mathrm{DLab}$.

Em Meu Amigãozão, a animação seriada coproduzida pela 2DLab e a canadense Breakthrough, houve $50 \%$ de investimento nacional na produção, maior envolvimento e poder de decisão da produtora e mobilização de mais de 80 profissionais brasileiros. A parceria de coprodução com a Breakthrough resultou em um contrato com a TV canadense Treehouse, "reconhecida internacionalmente pela qualidade de sua programação para o público pré-escolar".

A possibilidade de investimentos brasileiros proporcionou à 2DLab a manutenção dos direitos de propriedade da obra e, como observado, mobilização dos profissionais da animação no Brasil, o que contribuiu para o aprimoramento dos domínios relacionados à animação de todos os envolvidos. A equipe brasileira ficou responsável pelo storyboard e pela animação; as viagens ao Canadá e as discussões sobre o roteiro foram constantes. Os roteiros só eram aprovados após cinco revisões, e a Treehouse disponibilizou uma equipe pedagógica para tratar dos conceitos centrais e manter a série como um produto internacional, sem características que definissem região ou cultura de algum dos países envolvidos na produção (Gatti Junior; Gonçalves; Barbosa, 2014).

O estudo comparativo de Gatti Junior, Gonçalves e Barbosa (2014) incluiu a experiência da TV Pinguim e contribuiu para esta investigação no sentido de confirmar os condicionantes externos apresentados na seção anterior. Programas de financiamento e fomento no país não só beneficiaram individualmente as produtoras independentes, mas produziram valor ao mercado brasileiro de animação. A 2DLab, que contou com os investimentos nacionais, além de manter os direitos de propriedade, dispôs de maior grau de autonomia na gestão do projeto em relação ao caso da Flamma. Essas experiências foram de aprendizado aos gestores do mercado brasileiro de animação seriada. Ao longo dos anos, as produtoras desenvolveram projetos próprios e são consultoras em projetos de produtoras independentes brasileiras. 
A Flamma firmou contrato de coprodução para a série de animação Lupi e Baduki com a Birdo Filmes de Animação e contrato de consultoria e parceria comercial com a Cabong Studios para os projetos de séries de animação $A$ Lenda da Garota, Tatuagens do Vovô e Um desenho muito muito legal. O objetivo da parceria é "lapidar criativamente e viabilizar financeiramente os projetos" (Facebook Cabong Studios, 2018).

Em termos de coprodução, o projeto Lupi e Baduki indica a profissionalização do mercado brasileiro de animação, que, atualmente, também está presente em muitos outros projetos de obras seriadas com o intuito de distribuição internacional. Na bíblia da série, além da Birdo Filmes de Animação, outras duas empresas brasileiras assinam o projeto, potencializando o nível técnico da animação e a condição de promoção e distribuição: a MolToons (SP), que é especializada em animação, e a Elo Company (SP), que desenvolve estratégias de branded content ${ }^{1}$ no audiovisual, com conteúdo multiplataforma, e é referência em licenciamento nacional e internacional.

Com esses exemplos que, durante a investigação, emergiram como referências, tanto nos aspectos artísticos como nos processos de gestão, comprovou-se a evolução do diálogo entre os agentes que participam do campo da animação seriada infantil brasileira. As produtoras independentes brasileiras se especializaram e construíram redes de empresas e articularam profissionais capazes de apresentar a obra ao mercado nacional e internacional com credibilidade técnica, criativa e de gestão. Essa articulação está descrita a seguir com a identificação dos objetivos e das características na condução dos negócios de coprodução.

\section{OBJETIVOS E CARACTERÍSTICAS DA COPRODUÇÃO}

No início da década de 2010, as produtoras independentes brasileiras que investiam em animação atentaram para as possibilidades de submissão de projetos ao fomento público e coprodução de séries. O desafio era desenvolver e produzir projetos comerciais que tivessem a televisão como primeira janela de exibição. Seus gestores percebiam a necessidade de investimentos em recursos tecnológicos, ampliação e/ou formação da equipe e ampliação do diálogo com a cadeia produtiva do setor audiovisual.

Algumas dessas produtoras atuavam com sucesso no mercado publicitário, como a Cabong Studios e a Origem Produtora de Conteúdo, e outras se dedicavam a projetos autorais, como a Otto Desenhos Animados.

A Cabong Studios participou da animação do filme Pôneis Malditos, da Nissan. Criado pela agência internacional Lew'Lara/TBWA, o filme recebeu dez premiações por criatividade e desempenho nas redes sociais em 2011 (ESTADÃO, 2011).

A Origem Produtora de Conteúdo também produzia animação para publicidade e investia em projetos autorais. O curta-metragem Tadinha, que deu origem à série, foi coproduzido com a RX30 e ganhou prêmio de melhor animação brasileira no Festival Internacional de Cinema Infantil em 2011.

1 Promoção da obra audiovisual por meio de desenvolvimento de conteúdo para diversas plataformas relacionado ao objetivo da marca. O intuito é criar interação direta com o público consumidor pelo entretenimento. 
Já Otto Desenhos Animados foi fundada em 1978 e se tornou referência em animação underground no país. Ao longo dos anos, produziu os seguintes longas de animação para adultos: Rocky \& Hudson (1994), Wood \& Stock: sexo, orégano e rock'n roll (2006), Até que a Sbórnia nos separe (2013) e A Cidade dos Piratas (2018). Rocky \& Hudson foi uma tirinha criada em 1987 pelo cartunista Adão Iturrusgarai. Inspirou o longa-metragem e, em 2019, uma série com 13 episódios de sete minutos foi coproduzida com o Canal Brasil (Globosat).

Com esses exemplos e incluindo as outras produtoras independentes citadas na introdução, foi possível identificar objetivos gerais para a prospecção de coprodução por perfil de atuação de cada empresa. A produtora de conteúdo almejava uma coprodução para melhorar a qualidade artística da animação e a condição técnica para submissão de projetos ao fomento público, editais das iniciativas privadas e estatais; o estúdio de animação pretendia melhorar sua capacidade de gestão sobre a obra, somar conhecimentos técnicos e artísticos, estabelecer uma melhor relação de custo de produção x resultado final; já a produtora, que prestava serviços em diversas etapas de produção da obra audiovisual, desenvolvia portfólio diversificado e contava com equipe para atuar em todas as etapas do projeto, pretendia tratar das especificidades importantes para cada projeto ao almejar uma parceria para coprodução.

Além dos objetivos gerais por perfil, também foi possível destacar quatro características na condução dos negócios de coprodução. A primeira indica a prevalência da parceria com os canais TV Brasil e TV Cultura, que atuaram como integrantes e fortalecedores da política pública para o setor audiovisual na época; a segunda refere-se à coprodução com canais dos conglomerados de comunicação, que possibilitou a internacionalização das séries de animação; a terceira relaciona coprodução ao tempo de lançamento de cada obra; a quarta é resultado da reflexão sobre coprodução e localização geográfica das produtoras.

A presença da TV Brasil e da TV Cultura como principais parceiras e coprodutoras dos projetos selecionados na Chamada Pública Banco Regional de Desenvolvimento do Extremo Sul/Fundo Setorial Audiovisual (BRDE; ANCINE; FSA) Prodav 01/2012 foi característica bem evidente na investigação. Isso se deve ao contexto da época de incremento das políticas públicas e de programas de incentivo ao audiovisual nacional, incluindo a animação.

A programação infantil estava migrando dos canais abertos para os canais fechados; a TV Cultura, da Fundação Padre Anchieta, privilegiou suas janelas de exibição matinais e dos finais de semana para o público infantil; a TV Brasil cumpria o papel de televisão pública voltada para democratização do acesso, com produção e distribuição de conteúdo nacional em rede. Ao participar como player ${ }^{2}$ no NordesteLab em 2016, a TV Brasil declarou na ficha de demanda de projeto audiovisual para player que sua finalidade era "complementar e ampliar a oferta de conteúdo, oferecendo uma programação de natureza informativa, cultural, artística, científica e formadora da cidadania".

A TV Brasil e a TV Cultura foram as coprodutoras das primeiras temporadas das duas obras vencedoras do Anima TV, Carrapatos e Catapultas, da Zoom Elefante, e

2 Players de mercado são grupos de forte expressão na sua área e atuam no mercado com outras empresas, investindo e colaborando. 
Tromba Trem, do Copa Studio, reiterando a importância do protagonismo de canais brasileiros na autonomia das produtoras independentes dispostas a investir em conteúdo para o público infantil e animação seriada. Essas coproduções foram anteriores à Chamada Pública BRDE/ BRDE/ANCINE/FSA Prodav 01/2012 e artisticamente reconhecidas, não só por profissionais da área, mas também pela audiência dos canais. Outro caso anterior é o da TV Rá-Tim-Bum, também da Fundação Padre Anchieta (Rede Cultura ${ }^{3}$ ), que já coproduzia A Mansão Maluca do Professor Ambrósio, da Tortuga.

A segunda característica identificada na condução dos negócios relaciona a coprodução dos canais de conglomerados de comunicação - Gloob e Cartoon Network - ao número de episódios das séries de animação. As coproduções com o Gloob, da Globosat, resultaram em 52 episódios de 11 minutos a Osmar, a primeira fatia do pão de forma, da 44 Toons, e 65 episódios de onze 11 minutos a SOS Fada Manu, da Boutique Filmes. Esta, por sua vez, contou com a coprodução da Lightstar Studios, estúdio de animação com experiência internacional consolidada. Em 2012, a Lightstar Studios já havia participado da produção de dois filmes de animação indicados ao Oscar: Secret of Kells (2010) e Chico e Rita (2012).

A coprodução do Cartoon Network, da Warner Bros. Entertainment, resultou em 52 episódios de onze 11 minutos a Tromba Trem, do Copa Studio. A parceria impactou positivamente no portfólio do estúdio de animação, que manteve negócios com o canal em Historietas Assombradas (Para crianças malcriadas), coproduzida pela Glaz Entretenimento. O Copa Studio também produziu o primeiro desenho original do Cartoon Network América Latina, Irmão do Jorel, indicado para o Emmy Kids em 2019. Uma especificidade na coprodução de Tromba Trem é a presença da RioFilme, empresa vinculada à Secretaria Municipal de Cultura que, de acordo com seu website, atua nas áreas de distribuição, expansão do mercado exibidor e formação de público.

A Birdo produziu Oswaldo com 52 episódios de 11 minutos, mas a coprodução da segunda temporada foi realizada com a Symbiosys Entertainment, estúdio de animação indiano especializado em animação 2D e 3D. Nesses quatro casos é possível destacar a importância do investimento para produção dos 52 episódios, que proporciona condições de internacionalização da animação, já que canais internacionais, como o Cartoon Network América Latina, só negociam séries de animação com esse número mínimo de episódios. Já citada, A Mansão Maluca do Professor Ambrósio, da Tortuga, tem 80 episódios em quatro temporadas, mas a duração de cada episódio é, em média, de cinco minutos e 30 segundos (5'30").

A terceira característica está relacionada ao tempo de produção e lançamento da animação. Estabelecendo um comparativo entre as produções com mais de 52 episódios, (excluindo Tromba Trem, que participou do Anima TV, e A Mansão Maluca do Professor Ambrósio, que já vinha sendo produzida desde 2010), é possível observar que Oswaldo só foi lançado em 2017, ou seja, seis anos após a publicação do resultado da Chamada Pública BRDE/ANCINE/FSA Prodav 01/2012. Osmar, a primeira fatia do pão de forma foi lançado em 2013 e SOS Fada Manu em 2015. Em 2017 também foi lançada a

3 A Rede Cultura é formada pela Rádio Cultura Brasil, Cultura FM, TV Cultura, TV Cultura Educação, TV Rá-Tim-Bum e Univesp TV. 
série Planetorama, da Cabong, com coprodução da TV Cultura. Tadinha, da Origem, foi lançada em 2018, contou com coprodução da Truque, produtora independente local (Salvador/BA) e foi exibida pela TVE da Bahia. Pronta também em 2018, Filosofinhos, da Otto Desenhos Animados, foi negociada com canal público, que interrompeu o planejamento da programação em função de novas diretrizes governamentais, não havendo exibição. O estúdio de animação buscava a viabilização de exibição da série quando a pesquisa à qual este artigo se relaciona estava sendo finalizada em 2020.

A quarta característica relaciona o tempo de produção à localização das produtoras. A Cabong tem sede em Curitiba (PR), a Origem, em Salvador (BA), e a Otto Desenhos Animados, em Porto Alegre (RS). Todas estão fora do eixo Rio-São Paulo e não coproduziram com canais fechados e/ou internacionais em 2012. Há indicação de que estar no eixo Rio-São Paulo facilitou o diálogo, a criação de redes de negócios para coprodução e agilizou a produção e o lançamento das obras. O Quadro 3 resume a relação entre produtora, perfil, ano de lançamento da obra e parcerias de coprodução.

Quadro 3. Produtoras, obras de animação seriada selecionadas na Chamada Pública Banco Regional de Desenvolvimento do Extremo Sul/Fundo Setorial Audiovisual Prodav 01/2012 e respectivas coproduções.

\begin{tabular}{|c|c|c|c|c|}
\hline Produtora & Perfil & Obra & $\begin{array}{l}\text { Ano lançamento } \\
\text { da primeira } \\
\text { temporada }\end{array}$ & Coprodução \\
\hline Zoom Elefante & $\begin{array}{c}\text { Produtora de } \\
\text { conteúdo }\end{array}$ & $\begin{array}{l}\text { Carrapatos e } \\
\text { Catapultas }\end{array}$ & 2011 & $\begin{array}{l}\text { TV Brasil } \\
\text { TV Cultura }\end{array}$ \\
\hline \multirow[t]{2}{*}{ Copa Studio } & \multirow[t]{2}{*}{$\begin{array}{l}\text { Estúdio de } \\
\text { animação }\end{array}$} & Tromba Trem & 2011 & $\begin{array}{c}\text { TV Brasil } \\
\text { TV Cultura } \\
\text { Cartoon Network } \\
\text { Rio Filme }\end{array}$ \\
\hline & & $\begin{array}{c}\text { Historietas } \\
\text { Assombradas }\end{array}$ & 2013 & $\begin{array}{c}\text { Glaz } \\
\text { Entretenimento }\end{array}$ \\
\hline Tortuga Studios & Produtora & $\begin{array}{l}\text { A Mansão Maluca } \\
\text { do Professor } \\
\text { Ambrósio }\end{array}$ & $\begin{array}{c}2010 \\
\text { Duas primeiras } \\
\text { temporadas sem } \\
\text { Prodav }\end{array}$ & $\begin{array}{l}\text { TV RaTimBum } \\
\text { TV Cultura }\end{array}$ \\
\hline 44 Toons & $\begin{array}{l}\text { Estúdio de } \\
\text { Animação }\end{array}$ & $\begin{array}{l}\text { Osmar, a primeira } \\
\text { fatia do pão de } \\
\text { forma }\end{array}$ & 2013 & $\begin{array}{l}\text { Gloob } \\
\text { TV Cultura }\end{array}$ \\
\hline $\begin{array}{l}\text { Boutique Filmes } \\
\text { e Produções }\end{array}$ & $\begin{array}{l}\text { Produtora de } \\
\text { conteúdo }\end{array}$ & SOS Fada Manu & 2015 & $\begin{array}{c}\text { TV Brasil } \\
\text { Gloob } \\
\text { Lightstar Studios }\end{array}$ \\
\hline $\begin{array}{l}\text { Origem } \\
\text { Produtora }\end{array}$ & $\begin{array}{c}\text { Produtora de } \\
\text { conteúdo }\end{array}$ & Tadinha & 2018 & $\begin{array}{l}\text { Truq Produtora } \\
\text { de Cinema }\end{array}$ \\
\hline Cabong Studios & $\begin{array}{l}\text { Estúdio de } \\
\text { animação }\end{array}$ & Planetorama & 2017 & TV Cultura \\
\hline $\begin{array}{l}\text { Birdo Filmes de } \\
\text { Animação }\end{array}$ & $\begin{array}{l}\text { Estúdio de } \\
\text { animação }\end{array}$ & Oswaldo & 2017 & $\begin{array}{l}\text { Symbiosys } \\
\text { Entertainment } \\
\text { (Índia) }\end{array}$ \\
\hline $\begin{array}{l}\text { Otto Desenhos } \\
\text { Animados }\end{array}$ & $\begin{array}{l}\text { Estúdio de } \\
\text { animação }\end{array}$ & Filosofinhos & 2018 & - ------ \\
\hline
\end{tabular}

Fonte: elaborado pela autora. 
Importante destacar os casos da Cabong (estúdio de animação) e da Origem (produtora de conteúdo). As produtoras foram contempladas com editais de Núcleos Criativos (referente a outro condicionante externo: fomento) e, portanto, um conjunto de outras obras demandou a atenção dos gestores para estruturação de recursos técnicos e humanos e de novas parcerias comerciais paralelamente à gestão dos processos criativos das obras da Chamada Pública BRDE/ANCINE/FSA Prodav 01/2012. Esses fatores podem ter contribuído para o adiamento de lançamentos de Planetorama e Tadinha, respectivamente.

Nesses casos, as obras dos Núcleos Criativos foram desenvolvidas em menos tempo. Do Núcleo Criativo Anima Bahia, Fábulas de Bulcan (20 episódios de três minutos) começou a ser exibida no dia 12 de outubro de 2017 pelo canal infantil ZooMoo. Trata-se de uma série de animação coproduzida com a Truq Produtora de Cinema que já estava sendo distribuída pela Encripta ${ }^{4}$ e disponibilizada pela plataforma de streaming Play Kids quando começou a ser exibida no canal. Tori, a Detetive (13 episódios de sete minutos) também foi desenvolvida no Núcleo Criativo, em seguida selecionada para produção no Prodav 01, em 2016, e estreou no ZooMoo no início de 2018, antes da série Tadinha.

Como observado por Paulo Muppet, da Birdo, em uma aula disponível no canal da Quanta Academia (2020), o tempo de produção de uma animação seriada, que ele define como animação comercial, após a aprovação do storyboard é muito relativo: "após aprovação do storyboard, eu posso aumentar a equipe de animadores e diminuir o tempo de produção. Não existe um tempo fixo. Existe um tempo relativo em função do tamanho da sua equipe". Um dos projetos atuais da Birdo é Ninjin ${ }^{5}$ (2019), coproduzido com o Cartoon Network e Pocket Trap ${ }^{6}$. Um episódio de sete minutos da série de animação é produzido em seis semanas (em média) com equipe que inclui 19 animadores. Um contraste em relação a Oswaldo, aprovada em 2012, lançada em 2017, com contrato de coprodução apenas a partir da segunda temporada.

O fato é que, com a aprovação do storyboard, os condicionantes internos, que são controláveis pelos gestores, operam quase exclusivamente, porque o desenvolvimento da série, a estruturação da equipe e as negociações com prestadores de serviços e parceiros comerciais, condicionadas aos fatores externos, já foram cumpridas. Mas a fala de Muppet indica, mais uma vez, a necessidade de recursos humanos, que estão condicionados aos recursos financeiros, para acelerar a produção da animação seriada.

No caso das animações seriadas produzidas com fomento público, existe a dependência do recurso inicial. O dinheiro não é liberado logo após a publicação do resultado da chamada. E esse foi um dos principais pontos negativos indicados pelos gestores das obras: "demora para a liberação do financiamento do BRDE7" (depoimento de um(a) gestor(a) entrevistado, 2018).

4 A Encripta é especializada em licenciamento e distribuição de conteúdo audiovisual para diversos segmentos de mercado, principalmente plataformas digitais.

5 Segunda série de animação original do Cartoon Network Brasil (Irmão do Jorel é a primeira), baseada no jogo Ninjin: Clash of Carrots, da Pocket Trap.

6 Pocket Trap é um estúdio independente de desenvolvimento de jogos com sede em São Paulo (SP).

7 Banco Regional de Desenvolvimento do Extremo Sul 
Além disso, o valor obtido por meio do fomento não cobriu o valor total das obras $^{8}$, que, segundo os gestores, custaram muitas vezes mais que o dinheiro levantado por meio do recurso público. Assim, a coprodução foi percebida como condição fundamental para concretização das obras para produção de novas temporadas. Uma possibilidade era já inscrever o projeto com a coprodução internacional, desde que, como já citamos, observada a condição de obra brasileira. Mas as produtoras e os estúdios de animação brasileiros estavam estruturando suas equipes e seus processos em 2012:

Tivemos que reaprender tudo o que sabíamos para poder trabalhar em escala. A equipe nunca tinha feito um projeto com escopo e prazos tão desafiadores. Além do mais havia muitos animadores novos. O treinamento era diário e aplicado pelos supervisores. (Depoimento de um(a) gestor(a) entrevistado, 2018).

Como já apresentado no caso de Princesas do Mar, da Flamma, a coprodução internacional exige credibilidade e experiência da produtora que prospecta o acordo. Em 2012, as produtoras com mais tempo de mercado, como a Otto Desenhos Animados e a 44 Toons, tinham trajetória reconhecida com projetos impressos e atuavam com produção de longa-metragem e jogos, respectivamente. A animação seriada infantil foi um desafio para todas as produtoras independentes que submeteram propostas ao Prodav 01/2012.

Nas produtoras observadas, a coprodução com canais incrementou o capital econômico dos projetos e as condições de comercialização, entretanto impôs limites à autonomia das produtoras. O fato é que os "diálogos com coprodutores definem o resultado da obra", segundo o gestor de uma produtora de conteúdo. A declaração corrobora a orientação do gestor da Flamma, durante suas masterclasses: ao dialogar sobre uma coprodução, a produtora deve ter segurança acerca da essência do projeto, do que precisa ser preservado e o que não está em negociação. O que está fora desses limites pode ser dialogado, revisitado e alterado.

\section{O DIÁLOGO COM OS CANAIS}

A partir do relato dos gestores das obras, foi possível observar a coprodução com os canais operando de três modos, sem que um eliminasse o outro: acompanhamento, adaptação e restrição. No acompanhamento, todas as etapas são discutidas e aprovadas coletivamente com participação concomitante da produtora e do canal. Já quando ocorre a adaptação, o canal interfere em alguma etapa ou parte do projeto. Na restrição, são impostas as limitações e/ou cortes.

A seguir, reproduzimos três relatos sobre coprodução com canais fechados. $O$ primeiro ilustra o acompanhamento do canal durante todo o processo de execução da obra:

8 De acordo com as regras do FSA, o montante do investimento foi definido pelo Comitê de Investimentos e limitado a $95 \%$ do orçamento de produção e $80 \%$ do orçamento total do projeto. 
No começo do projeto das temporadas, temos algumas conversas com o canal para ver onde queremos chegar em termos de orçamento, cronograma e editoriais. Durante a produção, o canal acompanha etapa por etapa e vai aprovando. A equipe criativa/editorial do canal vai fazendo comentários em sinopses, storyboards, animatics, gravação de vozes em todas as etapas. Eles acompanham tudo." (Depoimento de um(a) gestor(a) entrevistado, 2018).

O segundo refere-se às adaptações em Osmar, a primeira fatia do pão de forma. A origem da narrativa é uma HQ underground que virou livro animado para público infantojuvenil. A 44 Toons relatou o que foi necessário para exibir a série no Gloob e na TV Cultura e para torná-la competitiva no mercado internacional:

\begin{abstract}
A parceria com o Gloob surgiu quando estávamos iniciando a pré-produção da série. Como a faixa etária do canal é mais jovem, foi preciso adequar o projeto para essa idade. Porém era importante manter o interesse do público mais velho, já que a TV Cultura entrou no projeto exatamente pelo diálogo com pré-adolescentes e adultos. Isso nos obrigou a desenvolver uma série "Família", isso é, uma série que possa ser apreciada por crianças e adultos. Isso nos obrigou a criar camadas distintas no roteiro, colocando piadas que funcionassem para adultos e crianças. [...] Para deixar a série preparada para as vendas internacionais, trouxemos um estúdio americano especializado em roteiros de animação. Os roteiros eram traduzidos para o inglês, eles faziam sugestões e criavam novas piadas (trabaIho conhecido como "Humor Punch Up"), os roteiros eram retraduzidos e finalizados pelo roteirista responsável. (BOTTI, 2013).
\end{abstract}

O terceiro revela que o acompanhamento dos canais e adaptações nas obras, relacionado à coprodução de canais fechados, foi percebido como mais rígido pelos gestores participantes desta pesquisa quando comparado aos relatos extraídos das entrevistas com criadores publicadas em sites especializados. Nesse sentido, os gestores entrevistados pontuaram as restrições de uma coprodução com canais:

\footnotetext{
Quando a coprodução com o canal foi firmada para as próximas temporadas, houve corte orçamentário e consequente orientação para que as novas histórias fossem criadas a partir de personagens, cenários, props e trilhas já existentes. [...] Foi necessário restringir, na sala de roteiros, as histórias para que nenhuma nova arte (personagem, props, cenário) fosse criada. Os roteiristas trabalharam com uma Bíblia com tudo que existia e precisavam adaptar da história a partir das artes disponíveis. Foi uma restrição orçamentária em função dos acordos de coprodução. (Depoimento de um(a) gestor(a) entrevistado, 2018).
}

As primeiras experiências em coprodução contribuíram com reflexões por parte dos gestores acerca dos impactos dos acompanhamentos, das adaptações e das restrições dos canais. Os limites impostos à produção exigiram aprimoramento da expansão narrativa das obras para novas temporadas e melhor compreensão dos processos produtivos das obras seriadas. Sobre essas questões, seguem dois depoimentos:

Precisamos desenvolver mais camadas de motivação [...] Os conflitos ficaram rasos. [...] Esquecemos o conflito da narrativa que precisa se aprofundar e transformar. Isso tem a ver com o arco dramático. Deve ter um arco dramá- 
tico da série e não ser apenas episódico. [...] a música brilha muito na série. Nas temporadas seguintes, existiu a biblioteca. [...] Ficamos um tempo sem compor novas músicas, apenas adaptando. Mas fez tanta falta, que vamos trazer de volta. (Depoimento de um(a) gestor(a) entrevistado, 2018).

Nosso aprendizado foi a melhoria da estrutura de processos de métodos para a produção de séries. (Depoimento de um(a) gestor(a) entrevistado, 2019).

Importante pontuar que os canais são vistos pelos gestores das produtoras independentes como parceiros, e as relações comerciais são colaborativas e positivas, mesmo quando há a percepção de regras mais rígidas, como é o caso de canais fechados para o público infantil. Esses canais segmentam o público por faixa etária, temas e abordagem, o que lhes confere diretrizes de identidade de marca e editorial que precisam ser rigorosamente seguidas. Qualquer obra deve ter aderência a essa proposta de identidade.

\section{CONCLUSÕES}

Foram observadas as experiências de produtoras independentes brasileiras que, em 2012, passavam pelas primeiras incursões de produção de obras de animação com fomento público e coprodução. O mercado brasileiro de animação seriada começava a se profissionalizar e os interesses das produtoras incluíam a consolidação do portfólio com obras de referência e prospecção de parcerias internacionais.

Com a criação de redes de negócios que viabilizaram as primeiras coproduções, todas as produtoras investigadas desenvolveram e aprimoraram domínios para elaboração de outros novos projetos com padrão de apresentação internacional e compatíveis com editais de fomento. A estruturação física e financeira dos projetos exigiu qualificação técnica e olhar estratégico dos gestores para etapas de pré e pós- produção, antes focados apenas nos aspectos de produção. Também se aperfeiçoaram na supervisão de roteiros e na preparação e adaptação artística do conteúdo para o formato de produção em escala.

Atualmente, as coproduções são prospectadas nos eventos, nos festivais e nas feiras de negócios da área. Para isso, as produtoras independentes precisam, além de desenvolver as bíblias dos projetos, viabilizar a participação da produtora nos eventos e contar com gestores preparados para os pitchings e para o fortalecimento de sua rede de empresas. Um(a) dos(as) gestores(as) entrevistados(as) declarou que "estavam mudando a forma de se apresentar" e todos evidenciaram a percepção de que os processos de gestão da animação precisavam ser repensados, reconfigurados e inovados.

O mercado e a formação de redes que operam criativamente são promissores. São 327 produtoras independentes registradas na Brasil Audiovisual Independente (BRAVI, 2020), autodeclaradas produtoras de animação. Podem atuar com criação, produção e gestão de conteúdo inovador em um setor que tem a produção baseada no alto crescimento de tecnologias de comunicação e informação e em processos colaborativos e inter-relacionados dos agentes que compõem sua cadeia produtiva e o consumo baseado na economia da experiência. 
Entretanto, apesar dos esforços planejados, constantes e perseverantes de diversos agentes do mercado de animação nacional relacionados ao aperfeiçoamento de políticas e fomento, à profissionalização, aos investimentos humanos e tecnológicos, o Brasil descontinuou a política pública para o setor. Os programas de fomento foram imprescindíveis ao desenvolvimento dos negócios das produtoras investigadas, mas gradativamente descontinuados antes de se consolidar uma indústria de animação brasileira, fragilizando todo o alicerce do mercado construído entre 2012 e 2018 e colocando todas as redes em caminhos incertos e inseguros.

\section{REFERENCIAS}

BRASIL. Instrução Normativa n 104 de 10 de julho de 2012. Dispõe sobre o Registro de Obra Audiovisual Não Publicitária Brasileira, a emissão de Certificado de Produto Brasileiro e dá outras providências. Agência Nacional do Cinema, 2012. Disponível em: https://www.ancine.gov.br/pt-br/ legislacao/instrucoes-normativas-consolidadas/instru-onormativa-n-104-de-10-de-julho-de-2012. Acesso em: 10 jan. 2018.

BRASIL. Lei $n^{\circ} 12.485$, de 12 de setembro de 2011 de Dispõe sobre a comunicação audiovisual de acesso condicionado; altera a Medida Provisória no 2.228-1, de 6 de setembro de 2001, e as Leis nos 11.437, de 28 de dezembro de 2006, 5.070, de 7 de julho de 1966, 8.977, de 6 de janeiro de 1995, e 9.472, de 16 de julho de 1997; e dá outras providências. Presidência da República. Casa Civil. Subchefia para Assuntos Jurídicos. Brasília, 2011. Disponível em: http://www.planalto.gov.br/ ccivil_03/_ato2011-2014/2011/lei/L12485.htm. Acesso em: 18 dez. 2018.

BRAVI. Série animada de sucesso, 'Oswaldo', da Birdo Studio, terá distribuição internacional. Brasil Audiovisual Independente, 2018. Disponível em: http://bravi.tv/serie-animada-de-sucesso-oswaldoda-birdo-studio-tera-distribuicao-internacional/. Acesso em: 18 dez. 2018.

BOTTI, G. Osmar: de HQ underground a série de TV. ComKids, 2013. Disponível em: https://comkids. com.br/osmar-de-hq-underground-a-serie-de-tv/. Acesso em: 10 nov. 2018.

BRDE; ANCINE; FSA. Chamada Pública BRDE/FSA PRODAV 01/2012. Disponível em: http://www.brde. com.br/fsa/chamadas-publicas/producao/chamada-publica-brdefsa-prodav-012012/. Acesso em: 18 dez. 2018.

ESTADÃO. "Pôneis Malditos" chega a 10 premiações. Estadão, 2011. Disponível em: https:// jornaldocarro.estadao.com.br/carros/poneis-malditos-chega-a-10-premiacoes/. Acesso em: 04 jul. 2018.

FONSECA, R. Produção de seriados de animação brasileiros se firma com 30 novos projetos em curso. O Globo Cultura, 2012. Disponível em: https://oglobo.globo.com/cultura/producao-deseriados-de-animacao-brasileiros-se-firma-com-30-novos-projetos-em-curso-5502416. Acesso em: 26 mar. 2018

GATTI JUNIOR, W.; GONCALVES, M. A.; BARBOSA, A. P. F. P. L. Um estudo exploratório sobre a indústria brasileira de animação para a TV. REAd - Revista Eletrônica de Administração, Porto Alegre, v. 20, n. 2, p. 461-495, 2014. https://doi.org/10.1590/1413-2311057201238250

IBOPE. Animação brasileira é líder de audiência. O Debate, 2009. Disponível em: https://www.odebate. com.br/na-tela/animacao-brasileira-e-lider-de-audiencia-26-05-2009.html. Acesso em: 05 abr. 2019.

KOTLER, P.; ARMSTRONG, G. Princípios de marketing. 15. ed. São Paulo: Pearson Education do Brasil, 2015.

KOTLER, P.; KELLER, K. L. Administração de marketing. São Paulo: Pearson Education do Brasil, 2016.

QUANTA ACADEMIA. Dicas de storyboard com Paulo Muppet. YouTube, 2020. Disponível em: https://www.youtube.com/watch?v=lb-hhAYTtqU\&t=2735s. Acesso em: 30 abr. 2020. 


\section{Sobre a autora}

Natacha Stefanini Canesso: Doutora em Comunicação e Cultura Contemporâneas pela Universidade Federal da Bahia (PósCom/UFBA). Professora da Universidade Federal do Oeste da Bahia - Centro Multidisciplinar de Santa Maria da Vitória - no curso de Publicidade e Propaganda. Pesquisadora da animação brasileira e das políticas públicas culturais. Integrante do CP-Redes (UFBA).

Conflito de interesses: nada a declarar - Fonte de financiamento: Fundação de Amparo à Pesquisa do Estado da Bahia (Fapesb). 